\title{
Brain Natriuretic Peptide in Liver Cirrhosis and Fatty Liver: Correlation with Cardiac Performance
}

\author{
Amna Metwaly ${ }^{1}$, Ashraf Abdel khalik ${ }^{1}$, Fatma Mohammad Nasr ${ }^{1}$, Amal Ismail Sabry ${ }^{1}$, Mohamed Fathy Gouda ${ }^{2}$, \\ Mona Hassan ${ }^{3}$
}

${ }^{1}$ Intensive Care Department, Theodor Bilharz Research Institute, Giza, Egypt

${ }^{2}$ Gastroenterology and Hepatology Department, Theodor Bilharz Research Institute, Giza, Egypt

${ }^{3}$ Clinical Chemistry Department, Theodor Bilharz Research Institute, Giza, Egypt

Type of article: Original

\begin{abstract}
Objective: The aims of the present study were to assess the serum BNP level in patients with post hepatitis C liver cirrhosis and patients with fatty liver and to determine the correlation between BNP and the severity of liver disease and cardiac performance.

Methods: The study was conducted on 140 subjects subdivided into 3 groups: group 1 included 60 patients having post hepatitis $\mathrm{C}$ virus (HCV) liver cirrhosis; group 2 included 60 patients with nonalcoholic fatty liver disease (NAFLD); and group 3 included 20 healthy volunteers serving as a control group. All patients and volunteers were subjected to full physical examinations, laboratory evaluation of hemoglobin percent, liver and renal function tests, serum electrolytes, cholesterol, triglyceride, HBs antigen, HCV antibody and serum BNP levels, ECG, abdominal ultrasonography, and echocardiography.

Results: There was a significant increase in the BNP level in cirrhotic patients compared to the other two groups $(p=0.000)$, and it was correlated with the severity of liver disease assigned as Child's classification $(p=0.000)$. Also, there was a significant increase in the BNP level in cirrhotic patients with decompensation components compared to those without decompensation components $(\mathrm{p}=0.000)$, history of hepatic encephalopathy $(\mathrm{p}=$ $0.000)$, history of variceal bleeding $(p=0.000)$, history of spontaneous bacterial peritonitis $(p=0.000)$, presence of ascites $(p=0.000)$ and portal vein diameter $>11 \mathrm{~mm}$ in abdominal ultrasound $(\mathrm{p}=0.000)$, and prolonged QTc interval in ECG $(p=0.011)$. There was a significant increase in serum BNP in patients with cirrhosis with the following echocardiographic findings: IVST $>11 \mathrm{~mm}$, PWT $>11 \mathrm{~mm}$, LA diameter $>40 \mathrm{~mm}, \mathrm{EF} \%<54 \%$, and E/A ratio $<1$ compared to those without these echocardiographic findings $(\mathrm{p}=0.000)$.

Conclusion: BNP level increases in post hepatitis $\mathrm{C}$ cirrhotic patients and tends to decrease in fatty liver disease patients, and it is correlated with both the severity of liver disease and the morpho-functional cardiac changes. Given the ever-increasing prevalence of liver cirrhosis and fatty liver disease worldwide, it is important to understand the benefits and limitations of BNP as a heart failure biomarker in hepatic patients, where the relationship between BNP level and myocardial function is complex and is altered by the liver disease.

Keywords: brain natriuretic peptide (BNP), post hepatitis $\mathrm{C}$ virus liver cirrhosis, fatty liver, echocardiography
\end{abstract}

\section{Introduction}

\subsection{Background and study logic}

Brain natriuretic peptide (BNP) is a cardiac neurohormone that is secreted from the ventricles in response to increased diastolic pressure or volume (1). When cirrhosis is present, the BNP concentrations may be higher (2). Several studies have shown elevated BNP levels are related to the severity of cirrhosis, myocardial hypertrophy, myocardial dysfunction, and QT prolongation $(3,4)$. Increased BNP concentrations in people who have liver cirrhosis may be due to the hyperdynamic state and cirrhotic cardiomyopathy. Pimenta et al. (2) observed that BNP level in cirrhosis reflects the cardiac systolic function and is an independent predictor of medium-term survival in

\section{Corresponding author:}

Fatma Mohammad Nasr, Intensive Care Department, Theodor Bilharz Research Institute, Giza, Egypt.

Tel: +20.1003542204, E-mail: fatma_elwakeel@live.com

Received: December 03, 2015, Accepted: January 18, 2016, Published: February 2016

iThenticate screening: January 18, 2016, English editing: January 28, 2016, Quality control: February 02, 2016

(C) 2016 The Authors. This is an open access article under the terms of the Creative Commons Attribution-NonCommercialNoDerivs License, which permits use and distribution in any medium, provided the original work is properly cited, the use is non-commercial and no modifications or adaptations are made. 
advanced cirrhosis. Padillo's study showed that increased baseline BNP concentrations, along with high Child and MELD scores, may be regarded as the critical cardiac dysfunction parameter in cirrhotic patients (5). Radvan et al. found a significant correlation between B-type natriuretic peptide in plasma and the severity of liver disease in cirrhotic patients. High plasma BNP appears to be a good negative prognostic factor of death from cirrhosis (6). Serum BNP levels were correlated positively with the Child score, the grade of esophageal varices, a history of spontaneous bacterial peritonitis, and the presence of ascites and collateral circulation. BNP levels that exceeded the median value were associated with an increased prevalence of death within 12 months after discharge (7). The association of metabolic syndrome (MetS) and non-alcoholic fatty liver disease (NAFLD) is so strong that the latter is considered as the hepatic manifestation of MetS $(8,9)$. Steatosis is associated with an increased prevalence and incidence of cardiovascular disease $(10,11)$, and several investigators have examined the association of NAFLD with subclinical cardiovascular disease CVD, e.g., carotid artery intima-media thickness or clinical CVD (12). Higher natriuretic peptide levels were characterized by decreased visceral and liver fat and increased lower body fat irrespective of age, gender, race, and obesity status. This suggested that there might be a link between the heart and adipose tissue distribution that is mediated through natriuretic peptides (13). A study of 608 Japanese patients with type 2 diabetes indicated that there was an inverse relationship between BNP and body mass index (BMI), with a more robust inverse association between BNP and visceral fat compared with other measures of adiposity (14). Also, in the Framingham Heart Study, inverse associations between BNP and visceral fat were similarly described based on a multivariable adjusted analysis, which included BMI, with no independent association seen with abdominal subcutaneous fat (15).

\subsection{Objective}

The general objective of this study was to evaluate serum BNP levels in two groups of chronic liver disease patients (post hepatitis $\mathrm{C}$ virus liver cirrhosis and fatty liver). The specific objective was to find its correlation with the severity of liver disease and cardiac performance.

\section{Material and Methods}

\subsection{Setting and patients}

The present study was conducted on 140 subjects from Theodor Bilharz Research Institute Hospital, selected to represent 3 groups:

1) Group 1: Included 60 patients having post hepatitis $C$ virus liver cirrhosis, which was diagnosed based on the results of laboratory tests (hepatitis $\mathrm{C}$ virus antibody, low serum concentrations of albumin, high INR and low platelet count) and abdominal ultrasonographic findings (irregularity of the liver's surface). The stage of cirrhosis was classified according to the Child-Pugh classification, which reflects the severity of the disease.

2) Group 2: Included 60 patients with NAFLD, which was diagnosed by a characteristic liver echo pattern (diffuse hyperechogenicity of liver compared with right kidney) and negative hepatitis markers. Grading of diffuse hepatic steatosis on ultrasound was used to evaluate the extent of fatty changes in the liver, grade I: increased hepatic echogenicity with visible periportal and diaphragmatic echogenicity; grade II: increased hepatic echogenicity with imperceptible periportal echogenicity, without obscuration of diaphragm; and grade III: increased hepatic echogenicity with imperceptible periportal echogenicity and obscuration of the diaphragm (16).

3) Group 3: Included 20 healthy volunteers, who were age and gender matched with the study groups, to serve as a control group with normal liver ultrasonography, normal liver function tests, and negative hepatitis markers.

\subsection{Exclusion criteria}

Subjects with histories of heart disease, diabetes mellitus, obesity (BMI > 25), hypertension (blood pressure $>$ 140/90 mmHg), dyslipidemia, acute or chronic kidney disease, any malignancy, pregnancy, anemia with hemoglobin less $10 \mathrm{gm} \%$, taking any medication with adverse effects on the liver or cardiovascular system, or alcohol consumption were excluded.

\subsection{Methods}

All patients and normal volunteers underwent:

1) Thorough histories and physical examinations

2) Blood sampling for serum electrolytes, cholesterol, triglyceride, HBs antigen and HCV antibody and liver and renal function tests 
3) Immunoassay for detection of BNP: Circulating BNP was determined by commercially available ELISA. The BNP ELISA kit allows in vitro quantitative determination of BNP concentrations in serum

4) Resting ECGs with 12 leads. The duration of the QT interval was calculated manually. The QT intervals were corrected in accordance with the rate using the BAZET formula, i.e., QTc $=\mathrm{QT} / \sqrt{ } \mathrm{RR} . \mathrm{QTc}>440 \mathrm{~ms}$ was considered prolonged $(17,18)$

5) Abdominal ultrasound scanning using a Toshiba Memo 30 scanner equipped with a $3.5 \mathrm{mHz}$ linear transducer

6) Echo-Doppler study: All echocardiographic measurements were performed according to the recommendations of the American Society of Echocardiography (19). M-mode, two-dimensional echocardiography, and Doppler ultrasound studies were conducted using a high resolution Toshiba Memo 30 scanner. Using the M-mode, measurements of interventricular septum (IVS) and left ventricle posterior wall (PWT) thicknesses were conducted and the diameters of the left ventricle end-diastolic (LVED) and end systolic (LVES) were determined. The left ventricular mass was calculated according to Devereux and associates' convention, i.e., LVM $(\mathrm{gm})=1.04 \times\{($ LVED + IVST+ PWT $) 3-$ LVED3 $\} \times 0.8+0.6(20)$. The diameter of the left atrium was determined from the parasternal long axis view at the end systole. The left ventricular ejection fraction (EF\%) was measured from M-mode dimensions using the Teichholz formula (21). The velocity of the mitral inflow early, rapid-filling wave (E), the peak velocity of the latefilling wave due to atrial contraction (A), and the E/A ratio also were measured.

\subsection{Research ethics}

The Ethics Committee of TBRI approved the study, and it was conducted in accordance with the Helsinki Declaration (1975). All participants gave written informed consent. The study was conducted in 2014 and 2015.

\subsection{Statistical Analysis}

Statistical analysis was performed using SPSS version 17. Data were expressed as the mean \pm standard deviation (SD) for numerical variables. $\mathrm{p} \leq 0.05$ was considered to be statistically significant, and $\mathrm{p} \leq 0.01$ was considered to be statistically highly significant.

\section{Results}

The demographic data of the patients with liver cirrhosis, those with steatosis, and that of the controls indicated that the mean ages were $43.67 \pm 9.46,44.87 \pm 7.4$, and $44.8 \pm 8.5$ years, respectively. In group 1, 40 were males $(66.67 \%)$, and 20 were females (33.33\%). In group 2, 45 were males $(75 \%)$, and 15 were females $(25 \%)$. In group 3 , 15 were males $(75 \%)$, and 5 were females $(25 \%)$. The laboratory data showed a statistically significant increase in serum sodium, alanine aminotransferase, total bilirubin, direct bilirubin, and serum albumin in patients with liver cirrhosis group and fatty liver group compared to the controls. Also, there was a statistically significant increase in serum potassium, aspartate aminotransferase, and brain natriuretic peptide in the patients with liver cirrhosis compared to the controls. There were statistically significant increases in serum sodium, serum potassium, alanine aminotransferase, aspartate aminotransferase, total bilirubin, direct bilirubin, and brain natriuretic peptide in patients with liver cirrhosis compared to those in the fatty liver group (Table 1). The electrocardiography data showed a statistically significant increase in corrected QT interval (QTc) in patients with liver cirrhosis and in the fatty liver group compared to the controls and also in patients in the liver cirrhosis group compared to the fatty liver group (Table 2). The echocardiographic data showed a statistically significant increase in the diameters of the left atrium and the aorta, as well as increases in the interventricular septum thickness (IVST), posterior wall thickness (PWT), end-systolic diameter (ESD), and left ventricular mass (LVM), in addition to a statistically-significant decrease in E/A in patients with liver cirrhosis and fatty liver compared to the controls. Also, there was a statistically significant increase in end-diastolic diameter (EDD) and decrease in ejection fraction (EF) in patients with fatty livers compared to the controls. Also, there was a statistically significant increase in posterior wall thickness (PWT) in patients with fatty livers compared to patients with liver cirrhosis (Table 2). There was a statistically significant increase in serum brain natriuretic peptide (BNP) in the group of patients with cirrhosis compared to the controls. There was a statistically significant increase in serum BNP in Child class B patients compared to Child class A patients. Also, there was a statistically significant increase in serum BNP in Child class C patients compared to Child class B patients (Table 3 ). 
Table 1. Laboratory data of the patients and control group

\begin{tabular}{|l|l|l|l|l|l|l|}
\hline Variables & Liver cirrhosis & Fatty liver & Control & $p_{I}$ value & $p_{2}$ value & $p_{3}$ value \\
\hline $\mathrm{Na}, \mathrm{mEq} / \mathrm{L}$ & $131.3 \pm 4.8$ & $138 \pm 3.1$ & $141.0 \pm 2.5$ & 0.000 & 0.000 & 0.000 \\
\hline $\mathrm{K}, \mathrm{mEq} / \mathrm{L}$ & $4.7 \pm 0.6$ & $4.0 \pm 0.4$ & $4.0 \pm 0.3$ & 0.000 & 0.169 & 0.000 \\
\hline Creat, mg/dL & 1.10 .5 & $0.9 \pm 0.3$ & $1.0 \pm 0.2$ & 0.603 & 0.169 & 0.009 \\
\hline BUN, mg/dL & $23.5 \pm 17.3$ & $26.2 \pm 5.9$ & $24.1 \pm 10.4$ & 0.883 & 0.259 & 0.251 \\
\hline ALT, U/L & $31.8 \pm 33.8$ & $16.7 \pm 3.3$ & $13.5 \pm 2.0$ & 0.015 & 0.000 & 0.000 \\
\hline AST, U/L & $65.9 \pm 88.8$ & $14.4 \pm 5.1$ & $13.3 \pm 4.2$ & 0.0009 & 0.377 & 0.000 \\
\hline T bil, $\mathrm{mg} / \mathrm{dL}$ & $3.4 \pm 4.3$ & $0.9 \pm 0.2$ & $0.5 \pm 0.1$ & 0.003 & 0.000 & 0.000 \\
\hline D bil, mg/dL & $1.8 \pm 2.7$ & $0.2 \pm 0.0$ & $0.1 \pm 0.0$ & 0.006 & 0.000 & 0.000 \\
\hline Alb, g/dL & $2.5 \pm 0.7$ & $3.8 \pm 0.6$ & $4.2 \pm 0.1$ & 0.000 & 0.004 & 0.000 \\
\hline BNP, $\mathrm{pg} / \mathrm{mL}$ & $165.0 \pm 12.4$ & $31.0 \pm 8.4$ & $33.8 \pm 7.2$ & 0.000 & 0.185 & 0.000 \\
\hline
\end{tabular}

$p_{1}$ value: significance between liver cirrhosis and control group, $p_{2}$ value: significance between fatty liver and control group, $p_{3}$ value: significance between liver cirrhosis and fatty liver group, Na: serum sodium, $\mathrm{K}$ : serum potassium, Creat: creatinine, BUN: blood urea nitrogen, ALT: alanine aminotransferase, AST: aspartate aminotransferase, $\mathrm{T}$ bil.: Total bilirubin, D bil.: Direct bilirubin, BNP: brain natriuretic peptide

Table 2. Electrocardiography and echocardiographic data of the patients and control group

\begin{tabular}{|l|l|l|l|l|l|l|}
\hline Variables & Liver cirrhosis & fatty liver & Control & $p_{1}$ value & $p_{2}$ value & $p_{3}$ value \\
\hline QTc, $\mathrm{msec}$ & $478.35 \pm 29.2$ & $422.43 \pm 26.7$ & $393.24 \pm 9.6$ & 0.000 & 0.000 & 0.000 \\
\hline LA, $\mathrm{mm}$ & $38.3 \pm 5.2$ & $39.5 \pm 6.5$ & $34.6 \pm 3.2$ & 0.003 & 0.001 & 0.258 \\
\hline $\mathrm{AO}, \mathrm{mm}$ & $30.3 \pm 3.2$ & $30.7 \pm 3.0$ & $28.4 \pm 2.5$ & 0.014 & 0.002 & 0.466 \\
\hline IVST, cm & $1.0 \pm 0.2$ & $1.04 \pm 0.3$ & $0.9 \pm 0.1$ & 0.035 & 0.044 & 0.391 \\
\hline PWT, cm & $1.0 \pm 0.1$ & $1.06 \pm 0.2$ & $0.9 \pm 0.1$ & 0.000 & 0.001 & 0.039 \\
\hline EDD, cm & $4.8 \pm 0.8$ & $4.9 \pm 0.9$ & $4.5 \pm 0.5$ & 0.073 & 0.035 & 0.467 \\
\hline ESD, cm & $3.0 \pm 0.7$ & $3.1 \pm 0.5$ & $2.7 \pm 0.5$ & 0.040 & 0.000 & 0.284 \\
\hline EF, $\%$ & $66.6 \pm 8.7$ & $65.7 \pm 7.9$ & $70.7 \pm 6.9$ & 0.056 & 0.012 & 0.549 \\
\hline LVM, gm & $183.0 \pm 52.1$ & $192.4 \pm 32.8$ & $136.8 \pm 29.2$ & 0.000 & 0.000 & 0.239 \\
\hline E/A & $0.82 \pm 0.16$ & $0.81 \pm 0.13$ & $1.21 \pm 0.36$ & 0.000 & 0.000 & 0.687 \\
\hline
\end{tabular}

$\mathrm{p}_{l}$ value: significance between liver cirrhosis and control groups, $p_{2}$ value: significance between fatty liver and control groups, $p_{3}$ value: significance between liver cirrhosis and fatty liver groups, QTc: Corrected QT interval, LA: left atrium diameter, Ao: aortic diameter, IVST: interventricular septum thickness, PWT: posterior wall thickness, EDD: end diastolic dimension, ESD: end systolic dimension, EF: ejection fraction, LVM: left ventricular mass, E/A: ratio of early rapid filling wave velocity of mitral inflow to peak velocity of the late filling wave due to atrial contraction

Table 3. BNP concentrations in patients with cirrhosis as related to their Child-Pugh classification

\begin{tabular}{|l|l|l|}
\hline Group (n) & BNP level & p-value \\
\hline Controls (20) & $33.8 \pm 7.2$ & \\
\hline Cirrhosis (60) & $165.0 \pm 12.4$ & 0.000 \\
\hline Child class A (6) & $91.4 \pm 9.6$ & \\
\hline Child class B (24) & $156.6 \pm 14.8$ & 0.000 \\
\hline Child class C (30) & $221.2 \pm 21.7$ & 0.000 \\
\hline
\end{tabular}

$\mathrm{BNP}=$ brain natriuretic peptide; $\mathrm{p}<0.000$ : cirrhosis group (total) compared to control group; $\mathrm{p}=0.000$ : child class $\mathrm{B}$ group compared to child class $\mathrm{A}$ group; $\mathrm{p}=0.000$ : child class $\mathrm{C}$ group compared to child class $\mathrm{B}$ group.

There was a statistically significant increase in serum brain natriuretic peptide (BNP) in patients with cirrhosis with decompensation components (history of hepatic encephalopathy, history of variceal bleeding, history of spontaneous bacterial peritonitis, presence of ascites and portal vein diameter $>11 \mathrm{~mm}$ in abdominal ultrasound and prolonged QTc interval in ECG) compared to patients without these decompensation components (Table 4). There was a statistically significant increase in serum brain natriuretic peptide (BNP) in patients with cirrhosis with the following echocardiographic findings: IVST $>11 \mathrm{~mm}$, PWT $>11 \mathrm{~mm}$, LA diameter $>40 \mathrm{~mm}, \mathrm{EF} \%<54 \%$, E/A ratio $<1$ compared to patients without these echocardiographic findings (Table 5). There was a statistically insignificant decrease in serum brain natriuretic peptide (BNP) in patients with steatosis compared to the controls. There was a 
statistically insignificant decrease in serum BNP in grade II patients compared to grade I patients. Also, there was a statistically insignificant decrease in serum BNP in grade III patients compared to grade II patients (Table 6). There was a statistically significant increase in serum brain natriuretic peptide (BNP) in patients with steatosis with the following echocardiographic findings: IVST $>11 \mathrm{~mm}$, PWT $>11 \mathrm{~mm}$, LA diameter $>40 \mathrm{~mm}, \mathrm{EF} \%<54 \%$, and E/A ratio $<1$ compared to patients without these echocardiographic findings (Table 7).

Table 4. BNP levels according to cirrhosis decompensation component

\begin{tabular}{|c|c|c|c|c|c|}
\hline \multirow[t]{2}{*}{ Component } & \multicolumn{5}{|c|}{ BNP levels } \\
\hline & $\mathrm{n}$ & Present, $\%$ & $\mathrm{n}$ & Absent & p-value \\
\hline History of hepatic encephalopathy & 50 & $167.1 \pm 16.3$ & 10 & $106.1 \pm 8.0$ & 0.000 \\
\hline History of variceal bleeding history & 15 & $198.1 \pm 14.3$ & 45 & $137.1 \pm 5.2$ & 0.000 \\
\hline History of spontaneous bacterial peritonitis & 20 & $169.3 \pm 12.7$ & 40 & $126.2 \pm 7.3$ & 0.000 \\
\hline Ascites & 55 & $184.2 \pm 13.2$ & 5 & $125.4 \pm 12.1$ & 0.000 \\
\hline Portal vein diameter $>11 \mathrm{~mm}$ & 55 & $155.7 \pm 8.4$ & 5 & $110.9 \pm 8.8$ & 0.000 \\
\hline Corrected QT interval $>440 \mathrm{~ms}$ & 10 & $484.37 \pm 10.5$ & 50 & $462.17 \pm 26.2$ & 0.011 \\
\hline
\end{tabular}

$\mathrm{BNP}=$ brain natriuretic peptide

Table 5. BNP levels according to echocardiographic findings in patients with liver cirrhosis

\begin{tabular}{|l|l|l|l|l|l|}
\hline \multirow{2}{*}{ Component } & \multicolumn{3}{l|}{ BNP levels } & \multicolumn{3}{l|}{} \\
\cline { 2 - 7 } & $\mathrm{n}$ & Present, \% & $\mathrm{n}$ & Absent & -value \\
\hline IVST $>11 \mathrm{~mm}$ & 12 & $155.8 \pm 9.3$ & 48 & $102.9 \pm 5.3$ & 0.000 \\
\hline PWT $>11 \mathrm{~mm}$ & 11 & $154.2 \pm 6.4$ & 49 & $97.9 \pm 8.8$ & 0.000 \\
\hline LA diameter $>40 \mathrm{~mm}$ & 18 & $157.4 \pm 7.5$ & 42 & $94.9 \pm 7.4$ & 0.000 \\
\hline EF\% $<54 \%$ & 4 & $158.7 \pm 8.4$ & 56 & $123.9 \pm 3.7$ & 0.000 \\
\hline E/A ratio $<1$ & 19 & $168.7 \pm 8.6$ & 41 & $93.2 \pm 3.4$ & 0.000 \\
\hline
\end{tabular}

$\mathrm{BNP}=$ brain natriuretic peptide, IVST: interventricular septum thickness, PWT: posterior wall thickness, LA: left atrium dimension, EF: ejection fraction, E/A: ratio of early rapid filling wave velocity of mitral inflow to peak velocity of the late filling wave due to atrial contraction.

Table 6. BNP concentrations in patients with steatosis as related to their ultrasound grading

\begin{tabular}{|l|l|l|l|}
\hline Group & $\mathrm{n}$ & BNP level & $\mathrm{p}$-value \\
\hline Controls & 20 & $33.8 \pm 7.2$ & \\
\hline Steatosis (total) & 60 & $31.0 \pm 8.4$ & 0.185 \\
\hline Grade I & 15 & $32.4 \pm 9.6$ & \\
\hline Grade II & 35 & $28.6 \pm 9.8$ & 0.212 \\
\hline Grade III & 10 & $24.2 \pm 7.7$ & 0.198 \\
\hline
\end{tabular}

$\mathrm{BNP}=$ brain natriuretic peptide, $\mathrm{P}<0.185$ : steatosis group (total) compared to control group; $\mathrm{p}=0.212$ : Grade II steatosis group compared to Grade I steatosis group; $\mathrm{P}=0.198$ : Grade III steatosis group compared to Grade II steatosis group.

Table 7. BNP levels according to echocardiographic findings in patients with steatosis

\begin{tabular}{|l|l|l|l|l|l|}
\hline \multirow{2}{*}{ Component } & \multicolumn{3}{l|}{ BNP levels } \\
\cline { 2 - 7 } & $\mathrm{n}$ & Present, \% & $\mathrm{n}$ & Absent & p-value \\
\hline IVST $>11 \mathrm{~mm}$ & 14 & $35.8 \pm 9.3$ & 46 & $22.9 \pm 5.3$ & 0.000 \\
\hline PWT $>11 \mathrm{~mm}$ & 12 & $34.2 \pm 6.4$ & 48 & $27.9 \pm 8.8$ & 0.023 \\
\hline LA diameter $>40 \mathrm{~mm}$ & 19 & $37.4 \pm 7.5$ & 41 & $24.9 \pm 7.4$ & 0.000 \\
\hline EF\% $<54 \%$ & 6 & $38.7 \pm 8.4$ & 54 & $23.9 \pm 3.7$ & 0.000 \\
\hline E/A ratio $<1$ & 29 & $39.3 \pm 8.6$ & 31 & $23.2 \pm 3.4$ & 0.000 \\
\hline
\end{tabular}

$\mathrm{BNP}=$ brain natriuretic peptide, IVST: interventricular septum thickness, PWT: posterior wall thickness, LA: left atrium diameter, EF: ejection fraction, E/A: ratio of early rapid filling wave velocity of mitral inflow to peak velocity of the late filling wave due to atrial contraction. 


\section{Discussion}

In our study, there was a statistically significant increase in serum BNP in patients with liver cirrhosis compared to fatty liver patients and the control group. Our study agrees with the studies of El Nakeeb et al. and Henrisken et al., who found a statistically significant higher level of circulating BNP concentration in patients with liver cirrhosis compared to the controls $(4,22)$. We found that serum BNP was significantly higher in Child class B patients compared to Child class A patients and in Child class $\mathrm{C}$ patients compared to Child class B patients. In agreement with our study, Henrisken et al. (4) found statistically significant higher BNP concentrations in patients with advanced grade of liver cirrhosis. Also, this was in agreement with Yilmaz et al. (23), who evaluated the relationship of increased serum BNP levels with the grade of liver cirrhosis and found a significant, positive correlation between BNP levels and higher grades of Child Pugh score, indicating that the BNP levels were related to severity of liver cirrhosis. Also, Shi et al showed that serum BNP levels were increased significantly in patients with cirrhosis compared to the controls; BNP concentrations were positively related to the severity of cirrhosis according to the Child-Pugh classification and the decompensation component of cirrhosis (7). Radvan et al. (6) reported a significant correlation between serum BNP levels and MELD scores. Our results showed a statistically significant increase in serum BNP in patients with cirrhosis with decompensation components, i.e., history of hepatic encephalopathy, variceal bleeding, and spontaneous bacterial peritonitis, ascites, portal vein diameter $>11 \mathrm{~mm}$ in abdominal ultrasound, and a prolonged QTc interval in ECG. This is in agreement with the findings of Krishnan et al. who concluded that the increased BNP concentrations in liver cirrhosis were associated with the decompensation components of cirrhosis, such as hepatic encephalopathy, esophageal varices, and ascites (24). Also, Henriksen et al. found that the concentration of circulating BNP was related to Child score and to arterial oxygen tension, heart rate, and QT interval (4). According to the results of the study of Yilmaz et al., the existence of ascites, collateral circulation, and esophageal varices were related to increased BNP levels (23). These findings were confirmed by the study of Shi et al., who found that the existence of ascites, collateral circulation, a history of spontaneous bacterial peritonitis, and esophageal varices were related to increased BNP levels. These findings indicated that BNP also might be a prediction tool to follow the clinical progress of patients with cirrhosis (7). In our study, there was a statistically significant increase in serum BNP in patients with cirrhosis with the following echocardiographic findings: interventricular septum thickness (IVT) $>11 \mathrm{~mm}$, posterior wall thickness $(\mathrm{PWT})>11 \mathrm{~mm}$, left atrium LA diameter $>40 \mathrm{~mm}$, ejection fraction $(\mathrm{EF}) \%<54 \%$, and E/A ratio $<1$ compared to the patients without these echocardiographic findings. Several studies have found that the increased serum BNP levels are correlated with the severity and functional capacity of chronic heart failure (1), and BNP increases in both systolic and diastolic dysfunction, but the increase is more pronounced when both are present $(25,26)$. In another study, BNP level was increased in correlation with the thickness of the ventricular walls, diastolic dysfunction, stress-induced systolic dysfunction, hyperdynamic circulation, and structural cardiac changes in patients with liver cirrhosis (27). Yilmaz et al. found significantly higher serum BNP levels in patients with a left ventricle posterior wall thickness $\geq 11 \mathrm{~mm}$ compared to patients with a wall thickness $<11 \mathrm{~mm}$ (23). BNP may be related to large atrial volumes. Myocardiocyte stretching is one of the main factors that stimulate the production of natriuretic hormones (1). BNP levels could be a marker of cardiovascular diastolic dysfunction in patients with end-stage liver disease (1, 3). Pimenta et al., in their study that included patients with decompensated cirrhosis, observed that BNP levels in cirrhosis reflect cardiac systolic function (2). These data suggest that BNP is a marker of cardiac subclinical dysfunction participating to liver decompensation. BNP levels are significantly associated to increased left atrial volumes and to signs of cardiac diastolic dysfunction, which characterize morpho-functional changes usually found in end-stage liver disease (28). Our study indicated that there were statistically significant increases in IVST, PWT, and LVM in the fatty liver group compared to the control group. These findings were similar to those of Goland et al., who found increased thickness of the interventricular septum, posterior wall, and larger left ventricular mass (LVM) and LV mass/height in the NAFLD group compared to the controls (29). We found significant increases in end diastolic diameter (EDD) and end systolic diameter (ESD) in the fatty liver group compared to the controls. Ramachandran et al. concluded that the increased echocardiographic left ventricular internal dimensions (EDD or ESD) are a risk factor for the development of congestive heart failure (30). Our study was inconsistent with the study of Fotbolcu et al., who found that patients with NAFLD have impaired LV systolic function, even in the absence of morbid obesity, hypertension, or diabetes (31). In our study, we found increased left atrium (LA) diameters and decreased E/A ratios (diastolic dysfunction) in patients who had fatty liver disease compared to the controls. Similar findings were reported by Serban et al. (32), who found a higher frequency of diastolic dysfunction in patients that had NAFLD compared to those without NAFLD. Bonapace et al. reported that, in patients that had NAFLD, even if the LV morphology and systolic function were preserved, early features of LV diastolic dysfunction may be detected (33). Also, inconsistent with our study, Aparci et al. (34) found significantly enlarged left atrial diameter and volume in patients with liver steatosis. In our study, we found a statistically insignificant 
decrease in BNP level in patients with liver steatosis compared to the controls. There was a statistically insignificant decrease in serum BNP in grade II steatosis patients compared to grade I patients and in grade III patients compared to grade II patients. We also found a statistically significant increase in serum BNP in patients with steatosis with the following echocardiographic findings: IVST $>11 \mathrm{~mm}$, PWT $>11 \mathrm{~mm}$, LA diameter $>40 \mathrm{~mm}$, EF\% $<54 \%$, and E/A ratio $<1$ compared to those without these echocardiographic findings. In many studies, fatty liver is considered a part of visceral fat (35-37). Cheng et al. (15) found an inverse relationship between BNP levels and visceral adipose mass. The reason decreased BNP levels in our fatty liver patients did not reach significance may be that we excluded obese and overweight patients from our study, and it also may be due to the presence of cardiac morphofunctional changes in some of our patients that increased their BNP levels, thereby counteracting the effect of visceral adiposity. In a study of 1873 community-based individuals, Cheng et al. (15) found an inverse relationship between BNP levels and visceral adipose mass. Also, in a Japanese study performed on 608 patients with type 2 diabetes, an inverse relationship between BNP and BMI was demonstrated with a more robust inverse association between BNP and visceral fat compared with other measures of adiposity (14). In the Framingham Heart Study, the inverse associations between BNP and visceral fat were described in a multi-variable, adjusted analysis that included BMI, and no independent association was observed with subcutaneous abdominal fat (15). Higher natriuretic peptide levels were associated independently with a favorable adiposity profile, which is characterized by decreased visceral and liver fat and increased lower body fat. Such a profile suggests that there might be a link between the heart and the distribution of adipose tissue that is mediated by natriuretic peptides (13). Although overweight and obese heart failure (HF) patients have relatively lower BNP levels, these levels still are predictive of worse symptoms, impaired hemodynamics, and higher mortality irrespective of the BMI level (38). Researchers have demonstrated a consistent inverse relationship between obesity (i.e., BMI $\geq 30$ ) and circulating BNP levels. In a study of 3,389 subjects without HF from the original Framingham Heart Study offspring cohort, Wang et al. (39) were the first to describe the inverse relationship between obesity and BNP levels. They adjusted the results of multi-variable regression analysis for echocardiographic variables, such as left atrial size left ventricular mass. The mean levels of BNP in plasma were 21.4, 15.5, and $12.7 \mathrm{pg} / \mathrm{mL}$ in lean (BMI <25), overweight (BMI of 25-29.9), and obese (BMI $\geq 30$ ), respectively. In the Dallas Heart Study, multi-variable regression models were adjusted for age, gender, ethnicity, left ventricular mass, hypertension, and end diastolic volume, and the results showed that higher BMI values were associated with lower levels of serum BNP $(\mathrm{p}<0.001)(40)$. Also, decreased BNP levels were observed in obese patients who had stable or acute CHF $(41,42)$.

\section{Conclusions}

BNP level increases in cirrhotic patients, and they are correlated with both the severity of liver cirrhosis and the morpho-functional cardiac changes. BNP level tends to be lower in fatty liver patients than in normal subjects, and they are insignificantly correlated with the severity of their fatty liver disease. Cardiac morphofunctional changes that occur in fatty liver disease patients alter their BNP levels. Given the ever-increasing prevalence of liver cirrhosis and fatty liver disease worldwide, it is important to understand the benefits and limitations of BNP as a heart failure biomarker in hepatic patients, where the relationship between BNP level and myocardial function is complex and is altered by the liver disease.

\section{Acknowledgments:}

This study was done in the Intensive Care Unit, Gastroenterology and Hepatology and Clinical Chemistry Departments at Theodor Bilharz Research Institute in Giza, Egypt. The authors gratefully acknowledge the help and support of the Research Center's staff.

\section{Conflict of Interest:}

There is no conflict of interest to be declared.

\section{Authors' contributions:}

All authors contributed to this project and article equally. All authors read and approved the final manuscript.

\section{References}

1) De Lemos JA, Mc Guire DK, Drazner MH. B-type natriuretic peptide in cardiovascular disease. Lancet. 2003; 362: 316-22. doi: 10.1016/S0140-6736(03)13976-1. 
2) Pimenta, J, Paulo C, Gomes A, Silva S, Rocha-Gonçalves F, Bettencourt P. B-type natriuretic peptide is related to cardiac function and prognosis in hospitalized patients with decompnesated cirrhosis. Liver International. 2010; 30: 1059-66. doi: 10.1111/j.1478-3231.2010.02266.x, PMID: 20492497.

3) Wong F, Siu S, Liu P, Blendis LM. Brain natriuretic peptide: is it a predictor of cardiomyopathy in cirrhosis? Clin Sci. 2001; 101: 621-8. doi: 10.1042/cs1010621, PMID: 11724649.

4) Henriksen JH, Gotze JP, Fuglsang S, Christensen E, Bendtsen F, Møller S. Increased circulating pro-brain natriuretic peptide (proBNP) and brain natriuretic peptide (BNP) in patients with cirrhosis: relation to cardiovascular dysfunction and severity of disease. Gut. 2003; 52: 1511-7. doi: 10.1136/gut.52.10.1511, PMID: 12970147.

5) Padillo J, Rioja P, Muñoz-Villanueva MC, Vallejo JA, Ciria R, Muntane J, et al. BNP as marker of heart dysfunction in patients with liver cirrhosis. Eur J Gastroenterol Hepatol. 2010; 22(11): 1331-6. doi: 10.1097/MEG.0b013e32833e6b2a, PMID: 20729741.

6) Radvan M, Svoboda P, Radvanová J, Stumar J, Scheer P. Brain natriuretic peptide in decompensation of liver cirrhosis in non-cardiac patients. Hepatogastroenterology. 2009; 56(89): 181-5. PMID: 19453054.

7) Shi LY, Jin R, Lin CJ, Wu JS, Chen XW, Yu Z, Zhang PC. B-type natriuretic peptide and cirrhosis Progression. Genet Mol Res. 2015; 14(2): 5188-96. doi: 10.4238/2015.May.18.9, PMID: 26125712.

8) Targher G, Arcaro G. Non-alcoholic fatty liver disease and increased risk of cardiovascular disease. Atherosclerosis. 2007; 19(12): 235-40. doi: 10.1016/j.atherosclerosis.2006.08.021, PMID: 16970951.

9) Marchesini G, Bugianesi E, Forlani G, Cerrelli F, Lenzi M, Manini R, et al. Nonalcoholic fatty liver, steatohepatitis, and the metabolic syndrome. Hepatology. 2003; 4: 917-23. doi: 10.1053/jhep.2003.50161, PMID: 12668987.

10) Hamaguchi M, Kojima T, Takeda N, Nagata C, Takeda J, Sarui H, et al. Nonalcoholic fatty liver disease is a novel predictor of cardiovascular disease. World J Gastroenterol. 2007; 13: 1579-84. doi: 10.3748/wjg.v13.i10.1579, PMID: 17461452, PMCID: PMC4146902.

11) Abid A, Taha O, Nseir W, Farah R, Grosovski M, Assy N. Soft drink consumption is associated with fatty liver disease independent of metabolic syndrome. J Hepatol. 2009; 51: 918-24. doi: 10.1016/j.jhep.2009.05.033, PMID: 19765850.

12) Targher G, Day CP, Bonora E. Risk of cardiovascular disease in patients with nonalcoholic fatty liver disease. N Engl J Med. 2010; 363: 1341-50. doi: 10.1056/NEJMra0912063, PMID: 20879883.

13) Neeland IJ, Winders BR, Ayers CR, Das SR, Chang AY, Berry JD, et al. Higher Natriuretic Peptide Levels Associate With a Favorable Adipose Tissue Distribution Profile. J Am Coll Cardiol. 2013; 62: 752-60. doi: 10.1016/j.jacc.2013.03.038, PMID: 23602771, PMCID: PMC3857334.

14) Sugisawa T, Kishimoto I, Kokubo Y, Nagumo A, Makino H, Miyamoto $Y$, et al. Visceral fat is negatively associated with B-type natriuretic peptide levels in patients with advanced type 2 diabetes. Diabetes Res Clin Pract. 2010; 89: 174-80. doi: 10.1016/j.diabres.2010.03.012, PMID: 20363521.

15) Cheng S, Fox CS, Larson MG, Massaro JM, McCabe EL, Khan AM, et al. Relation of visceral adiposity to circulating natriuretic peptides in ambulatory individuals. Am J Cardiol. 2011; 108: 979-84. doi: 10.1016/j.amjcard.2011.05.033, PMID: 21813106, PMCID: PMC3175269.

16) Singh D, Das CJ, Baruah MP. Imaging of non alcoholic fatty liver disease: A road less travelled. Indian J Endocrinol Metab. 2013; 17(6): 990-5. doi: 10.4103/2230-8210.122606, PMID: 24381873, PMCID: PMC3872717.

17) Goldman MJ. Principles of clinical electrocardiography. 8th ed. Los Altos: Lange Medical cary. 1973; 248.

18) Bernardi M, Calandra S, Colantoni A, Trevisani F, Raimondo ML, Sica G, et al. Q-T Interval Prolongation in Cirrhosis: Prevalence, Relationship With Severity, and Etiology of the Disease and Possible Pathogenetic Factors. Hepatology. 1989; 27: 28-34. doi: 10.1002/hep.510270106, PMID: 9425913.

19) Gottdiener JS, Bendnarz I, Devereaux R, Gardin J, Klein A, Manning WJ, et al. American Society of Echocardiography recommendations for use of echocardiography in clinical trials. J Am Soc Echocardiogr. 2004; (17): 1086-119. doi: 10.1016/j.echo.2004.07.013, PMID: 15452478.

20) Devereaux RB, Alonso DR, Lutas EM, Gottlieb GJ, Campo E, Sachs I, et al. Echocardiographic assessment of left ventricular hypertrophy: Comparison to necropsy findings. Am J Cardiol. 1986; 57: 450-8. doi: 10.1016/0002-9149(86)90771-X, PMID: 2936235.

21) Teichholz LE, Kreulen T, Herman MV, Gorlin R. Problems in echocardiographic volume determinations: echocardiographic-angiographic correlations in the presence of absence of asynergy. Am J Cardiol. 1976; 37(1): 7-11. doi: 10.1016/0002-9149(76)90491-4, PMID: 1244736. 
22) El Nakeeb NA, Esmat I, Bahaa M, Agwa SHA, Heidar MM. Evaluation of Cirrhotic Cardiomyopathy in Patients with Liver cirrhosis by Brain Natriuretic Peptide and Echocardiography Pre and Post Liver Transplantation. Life Science Journal. 2013; 10(2): 212-9.

23) Yilmaz VT, Eken C, Avci AB, Duman A, Tuna Y, Akin M. Relationship of increased serum brain natriuretic peptide levels with hepatic failure, portal hypertension and treatment in patients with cirrhosis. Turk J Gastroenterol. 2010; 21(4): 381-6. PMID: 21331991.

24) Krishnan A, Srinivasan V, Venkataraman J. Variceal recurrence, rebleeding rates and alterations in clinical and laboratory parameters following post-variceal obliteration using endoscopic sclerotherapy. J Dig Dis. 2012; 596-600. doi: 10.1111/j.1751-2980.2012.00633.x, PMID: 23107447.

25) Redfield MR, Mahoney DW, Jacopsen SJ. Isolated diastolic dysfunction in the community. Circulation. 1999; Suppl: I-381

26) Maisel A. B-type natriuretic peptide in the diagnosis and management of congestive heart failure. Cardiol Clin. 2001; 16: 557-71. doi: 10.1016/S0733-8651(05)70243-5.

27) Sharara AI, Rockey DC. Gastroesophageal variceal hemorrhage. N Engl J Med. 2001; 324: 669-81. doi: 10.1056/NEJMra003007, PMID: 11547722.

28) Licata A, Corrao S, Petta S, Genco C, Cardillo M, Calvaruso V, et al. NT Pro BNP Plasma Level and Atrial Volume Are Linked to the Severity of Liver Cirrhosis. PLoS ONE. 2013; 8(8): e68364. doi:10.1371/journal.pone.0068364.

29) Goland S, Shimoni S, Zornitzki T, Knobler H, Azoulai O, Lutaty G, et al. Cardiac abnormalities as a new manifestation of nonalcoholic fatty liver disease: echocardiographic and tissue Doppler imaging assessment. J Clin Gastroenterol. 2006; 40(10): 949-55. doi: 10.1097/01.mcg.0000225668.53673.e6, PMID: 17063117.

30) Ramachandran S, Vasan MD, Martin G, Larson ScD, Emelia J, Benjamin MD, et al. Left Ventricular Dilatation and the Risk of Congestive Heart Failure in People without Myocardial Infarction. N Engl J Med. 1997; 336: 1350-5. doi: 10.1056/NEJM199705083361903, PMID: 9134875.

31) Fotbolcu H, Yakar T, Duman D, Karaahmet T, Tigen K, Cevik C, et al. Impairment of the left ventricular systolic and diastolic function in patients with non-alcoholic fatty liver disease. Cardiol J. 2010; 17(5): 45763. PMID: 20865675.

32) Şerban A, Casoinic F, Bădău C. Diastolic dysfunction assessment by pulsed-wave and tissue Doppler imaging in diabetic patients with nonalcoholic fatty liver disease. HVM Bioflux. 2012; 4(2): 58-62.

33) Bonapace S, Perseghin G, Molon G, Canali G, Bertolini L, Zoppini G, et al. Nonalcoholic Fatty Liver Disease Is Associated With Left Ventricular Diastolic Dysfunction in Patients With Type 2 Diabetes. Diabetes Care. 2012; 35: 389-95. doi: 10.2337/dc11-1820, PMID: 22210573 , PMCID: PMC3263884.

34) Aparci M, Isilak Z, Uz O, Kardesoglu E, Yiginer O, Sildiroglu O, et al. Increased P wave dispersion in patients with liver steatosis. Med Glas (Zenica). 2010; 7(2): 143-7. PMID: 21258310.

35) Westerbacka J, Corner A, Tiikkainen M, Tamminen M, Vehkavaara S, Häkkinen AM, et al. Women and men have similar amounts of liver and intra-abdominal fat, despite more subcutaneous fat in women: implications for sex differences in markers of cardiovascular risk. Diabetologia. 2004; 47: 1360-9. doi: 10.1007/s00125-004-1460-1, PMID: 15309287.

36) Pietilainen KH, Rissanen A, Kaprio J, Mäkimattila S, Häkkinen AM, Westerbacka J, et al. Acquired obesity is associated with increased liver fat, intra-abdominal fat, and insulin resistance in young adult monozygotic twins. Am J Physiol Endocrinol Metab. 2005; 288: 768-74. doi: 10.1152/ajpendo.00381.2004, PMID: 15585588.

37) Thamer C, Machann J, Haap M, Stefan N, Heller E, Schnödt B, et al. Intrahepatic lipids are predicted by visceral adipose tissue mass in healthy subjects. Diabetes Care. 2004; 27: 2726-9. doi: 10.2337/diacare.27.11.2726, PMID: 15505012 .

38) Horwich MD, Hamilton MD, Fonarow GC. B-Type Natriuretic Peptide Levels in Obese Patients With Advanced Heart Failure. J Am Coll Cardiol. 2006; 47: 85-90.

39) Wang T, Larson M, Levy D, Benjamin E, Leip E, Wilson P, Ramachandran S. Impact of Obesity on Plasma Natriuretic Peptide Levels. Circulation. 2004; 109: 594-600. doi: 10.1161/01.CIR.0000112582.16683.EA, PMID: 14769680.

40) Das SR, Drazner MH, Dries DL, Vega GL, Stanek HG, Abdullah SM, et al. Impact of Body Mass and Body Composition on Circulating Levels of Natriuretic Peptides: Results from the Dallas Heart Study. Circulation. 2005; 112: 2163-8. doi: 10.1161/CIRCULATIONAHA.105.555573, PMID: 16203929. 
41) Frankenstein L, Remppis A, Nelles M, Schaelling B, Schellberg D, Katus H, et al. Relation of N-terminal pro-brain natriuretic peptide levels and their prognostic power in chronic stable heart failure to obesity status. Eur Heart J. 2008; 29: 2634-40. doi: 10.1093/eurheartj/ehn388, PMID: 18765456.

42) Krauser D, Chae C, Cameron R, Anwaruddin S, Baggish A, Chen A, et al. Effect of body mass index on natriuretic peptide levels in patients with acute congestive heart failure: A ProBNP Investigation of Dyspnea in the Emergency Department (PRIDE) substudy. Am Heart J. 2005; 149: 44-50. doi: 10.1016/j.ahj.2004.07.010, PMID: 15990762. 